\title{
Original
}

\section{Impact of rest breaks on musculoskeletal discomfort of Chikan embroiderers of West Bengal, India: a follow up field study}

\author{
Sabarni Chakrabarty ${ }^{1}$, Krishnendu Sarkar ${ }^{1}$, Samrat Dev ${ }^{1}$, Tamal Das ${ }^{2}$, \\ Kalpita Mitra ${ }^{1}$, Subhashis Sahu ${ }^{3}$ and Somnath Gangopadhyay ${ }^{1}$
}

\begin{abstract}
${ }^{1}$ Occupational Ergonomics Laboratory, Department of Physiology, University College of Science and Technology, University of Calcutta, India, ${ }^{2}$ Department of Physiology, Vidyasagar Evening College, 39 Sankar Ghosh Lane, Kolkata, West Bengal, India and ${ }^{3}$ Department of Physiology, University of Kalyani, Kalyani, Nadia, West Bengal, India
\end{abstract}

\begin{abstract}
Objectives: This study aimed to determine risk factors that predict musculoskeletal discomfort in Chikan embroiderers of West Bengal, India, and to compare the effect of two rest break schedules to reduce these symptoms. Methods: The Nordic musculoskeletal questionnaire was performed on 400 Chikan embroiderers at baseline containing questions on job autonomy, working behavior, and work stress factors. Relative risk was calculated to identify prognostic factors for musculoskeletal discomfort in different body regions. Two groups of workers received two rest break schedules for 4 months and compared in a between-subject design. Outcome variables were scores of Body Part Discomfort (BPD) scale. Results: Chikan embroiderers are afflicted with musculoskeletal discomfort mainly in the lower back, neck/shoulder and wrist/forearm region, which is attributed to their prolonged working timeinvolving hands and wrists, being in a static seating posture. Rigidity in working methods, prolonged working time, inadequate rest break during the working day, dissatisfaction regarding earning, monotonous work, static sitting posture, and repetitive movement of wrist and forearm were the significant predictors of these symptom developments. Rest break schedule 1 with more frequent and shorter breaks had more significant improvement on the severity of these musculoskeletal discomforts. Conclusions: Chikan embroiderers perform a highly dreary occupation and various ergonomics conditions work as predictors for
\end{abstract}

Received September 10, 2014; Accepted April 12, 2016

Published online in J-STAGE June 6, 2016

Correspondence to: S. Gangopadhyay, Occupational Ergonomics Laboratory, Department of Physiology, University College of Science and Technology, University of Calcutta, 13 Katua Kuthi Lane, Bhowanipur, Kolkata, 700 025, India (e-mail: ganguly1961@gmail.com and ganguly1 $961 @ y a h o o . c o m)$ developing musculoskeletal discomforts among them. Design of proper rest break schedule involving shorter and frequent breaks was competent for reducing these discomforts to a certain extent.

(J Occup Health 2016; 58: 365-372)

doi: 10.1539/joh.14-0209-OA

Key words: Ergonomics conditions, Musculoskeletal discomfort, Rest break schedules, Women

\section{Introduction}

Chikan embroidery is one of the most pristine handicrafts, usually performed by women living in rural areas in West Bengal, India. Chikan embroiderers are a part of the unorganized occupational sector. They belong to lower socioeconomic classes of the society. The available evidence suggests that craftwork is a major part of a country's economy, and home-based work is an important source of employment worldwide, particularly for women $^{1,2)}$. Although there are no reliable approximations of the number of embroiderers worldwide, WilkinsonWeber estimates that there are between 30,000 and $1,00,000$ in India ${ }^{3)}$. Chikan embroiderers work from home and do not have a fixed monthly income; however, they are paid in piece-rates. Women spend considerable amount of time embroidering sarees and salwaar suits. One piece requires approximately 3 days and is typically sold for approximately 40 Indian Rupees (INR; $<\$ 1$ USD). To ensure a regular earning, they rigorously work throughout the year. Furthermore, because Chikan embroidery work is often considered a leisure-time activity and therefore unworthy of special consideration and appropriate wages, organization and advocacy for improved working conditions is particularlydifficult ${ }^{4)}$. Chikan em- 
broidery entails repetitive movements of the wrists and forearms while maintaining a static sitting posture with a curved upper back and the head bent over the fabric. These working conditions predispose the occurrence of musculoskeletal discomfort in different body regions in seated workers. Studies have shown that women are more likely to suffer from musculoskeletal illnesses in the upper limbs and lower back ${ }^{5-7)}$. Choobineh et al found that static sitting postures, common among carpet weavers, were associated with a high rate of musculoskeletal complications in the lower back and shoulder ${ }^{8}$. Literature has shown that physically or psychologically demanding jobs are associated with higher prevalence of neck and back pain $^{9)}$. Pain conditions in different body regions are associated with poor socioeconomic conditions \& lifestyle factors as revealed by Bingefors et $\mathrm{al}^{10)}$. The work/rest pattern in a work cycle time is an important measurefor assessing the risk of development of musculoskeletal disorders in repetitive monotonous work ${ }^{11}$. Previous qualitative studies evaluated various rest break schedules with breaks ranging from $10 \mathrm{~s}$ "micro breaks" every $6 \mathrm{~min}$ to 15 min breaks every $2 \mathrm{~h}$, which have demonstrated that musculoskeletal discomfort can be reduced by increasing the frequency of rest breaks ${ }^{12-16)}$. Swanson and Sauter in a controlled study proved that frequent, short breaks distributed toward a work shift caused significant reduction in discomfort feeling ${ }^{17}$.

The present study aimed to investigate self-reported factors as probable predictors for musculoskeletal discomfort in different body parts and to find any significant effect of frequent short rest breaks on the well-being of the Chikan embroiderers of West Bengal, India. Body part discomfort (BPD) scale ratings were obtained from two groups of embroiderers who received two rest break schedules at 4-month intervals. The main hypothesis of the study was that frequent short rest pauses can provide better effect on discomfort feeling of the Chikan embroiderers.

\section{Materials and methods}

\section{Study population}

The present study was conducted among women Chikan embroiderers of Babnan, Hooghly in West Bengal, India. Babnan is a traditional center of Chikan embroidery and is constituted of two villages, Mulgram and Dargapada, with approximately 600 women engaged in the work. A lottery system was used and every alternate house of these villages was visited, and women performing Chikan embroidery were requested to participate in this study. A total of 400 Chikan embroiderers were randomly selected using simple random sampling method to participate in the study. Every willing participant was selected by offering monetary incentive to mitigate any bias. For eligibility to participate, women required to have been working as Chikan embroiderers for at least 5 years. Women with a history of rheumatoid arthritis, diabetes mellitus, or who were $>3$ months pregnant were excluded from the study.

The authors conducted multiple visits to the embroiderers to explain the aims of the study, and informed consent was obtained prior to their participation in this study. Ethical approval for this study was provided by Human Research Ethics Committee of the researchers' academic institution.

\section{Data Collection}

Interviews and direct observation were used to collect information about the demographics, occupational history, salary, and health history of the embroiderers. All interviews were completed individually.

Heights and weights of the embroiderers were measured using Martin's Anthropometer and a Crown weighing machine (Mfg. by Raymon Surgical Co.).

\section{Questionnaire study}

The Nordic musculoskeletal questionnaire was administered to all embroiderers ${ }^{18)}$. A reference number was covertly assigned to each participant. These numbers were used as identifiers on questionnaires to ensure data confidentiality.

The validity of this questionnaire has been evaluated by various researchers, and they have suggested that the Nordic Questionnaire offers substantial reliability ${ }^{19,20)}$. Palmer et al have concluded that the Nordic questionnaire is repeatable and sensitive and is likely to have a high utility in screening and surveillance ${ }^{21)}$. The Nordic musculoskeletal questionnaire is a self-reported measure and contains a series of objective questions with multiplechoice responses.

\section{Exposure measures}

Exposure parameters for development of musculoskeletal disorders consisted of questions gathered from the Nordic musculoskeletal questionnaire. The questions used to assess the job autonomy of the embroiderers included the following: i) whether there was rigidity in the work methods, ii) working time in a particular day, and iii) number of rest breaks during the working day. Questions on working behavior were associated with i) earning and ii) conflict regarding family caretaker and wage earner. Work stress factors included questions associated with i) job pattern, ii) posture, iii) difficulty in falling asleep, and iv) repetitive movement of wrist and forearm during embroidering.

\section{Rest break schedules}

The two rest break schedules assessed in this study were proposed as "Rest break schedule 1" and "Rest break schedule 2." The "Rest break schedule 1" was de- 
signed as 30-minwork/5-min rest and the "Rest break schedule 2" was designed as 60-min work/10-min rest. During interviewing, it was noticed that the embroiderers generally work for $6 \mathrm{~h}$ a day. Thus, the "Rest break schedule 1" included a 5-min break after every $25 \mathrm{~min}$ of work and the "Rest break schedule 2" included a 10-min break after every $50 \mathrm{~min}$ of work. For a $6 \mathrm{~h}$ working schedule, the "Rest break schedule 1" provided 12 breaks and the "Rest break schedule 2" provided 6 breaks. Under each schedule, a 30-min lunch period, additional to the 6 $\mathrm{h}$ of work and break time, occurred in the middle of the total working time.

Electrical timers were used to signal the scheduled breaks. The authors along with the supervisors of the embroidery sector used the timers and monitored the participants, such that they could consistently take breaks at appropriate times.

\section{Outcome measure}

Outcome variables were the scores on body part discomfort (BPD) scale. BPD is a self-reported objective rating of pain used to quantify the respondent's direct experience of discomfort in different body parts ${ }^{22}$. This is a 0 10 -point scale to measure the discomfort, where 10 indicated the worst imaginable discomfort and 0 indicated no discomfort. The BPD scale was applied to the participants at baseline and at the end of the study.

\section{Experimental protocol}

A between-subjects design was used for this study, which facilitated comparison of the effects of the two rest break schedules on the participants by minimizing the potential influence of a particular rest break schedule on the other.

A total of 200 participants were randomly selected from the total of 400 subjects and assigned to each rest break schedule. Therefore, a card-drawing method of simple random sampling was used. Data were collected between January and May of 2013.

\section{Instructions for rest break schedules}

Before beginning the study, participants attended an orientation program to receive instructions regarding the rest break schedules. Participants were instructed to follow the assigned rest break schedules as closely as possible. They were encouraged to get up and take at least a short walk away from their workstations during each break.

\section{Statistical analysis}

Data were analyzed using SPSS v.20. The mean and standard deviation of the subject characteristics were calculated. Relative risk was calculated to study the associations between musculoskeletal discomfort in different body parts of the participants and job autonomy, working
Table 1. Characteristics of the study population $(n=400)$

\begin{tabular}{lrr}
\hline \multirow{2}{*}{\multicolumn{1}{c}{ Individual characteristics }} & \multicolumn{2}{c}{ Index value } \\
\cline { 2 - 3 } & Mean & SD \\
\hline Age (years) & 27.1 & 2.8 \\
Height $(\mathrm{cm})$ & 151.4 & 4.9 \\
Weight $(\mathrm{kg})$ & 51.8 & 9.1 \\
Years of Experience (years) & 12.0 & 2.8 \\
Regular working hours & 6.0 & 1.9 \\
No. of breaks in a day & 1.7 & 0.7 \\
Monthly income (in INR) & 222.1 & 74.8 \\
\hline
\end{tabular}

INR=Indian Rupee; $\mathrm{SD}=$ Standard Deviation

behavior, and work stress factors. The effect of each rest break schedule on the severity of musculoskeletal discomfort based on BPD scale rating was tested using Student's t-test and $\mathrm{p}<0.05$ was considered to be significant. Results of the two rest break schedules on BPD scale rating were expressed as effect sizes, which were computed with Cohen's d (i.e., difference in means divided by the between-subjects SD) to enable direct comparison of the outcomes.

\section{Results}

\section{Subject characteristics}

Table 1 depicts that the study participants had an average working experience of 12 years and they worked for $6 \mathrm{~h}$ a day. On an average they received 1-2 breaks in the total working time in a day. Their average monthly income ranged between 200/- and300/- INR (\$3-\$5 USD).

\section{Questionnaire analysis}

Nordic musculoskeletal questionnaire analysis revealed that the embroiderers experienced pain in multiple parts of their body. Approximately $90 \%$ of the respondents suffered from lower back pain, $75 \%$ of them suffered from neck/shoulder pain, $68 \%$ of them suffered from wrist/ forearm pain, and $42 \%$ of them suffered from leg pain (Fig. 1).

\section{Relative risk calculation}

Results of the comparison between the two groups of embroiderers with their views regarding job autonomy, working behavior, and work stress factors obtained from the responses of Nordic musculoskeletal questionnaire are shown in Table 2. These responses are participatory in nature, i.e., gathered from the subjects through interview. Among the job autonomy factors, rigidity in work methods, prolonged working time, and inadequate rest break during the working day were the significant predictors of symptom development in the lower back, neck/shoulder, and wrist/forearm. Among the working behavior, dissatis- 


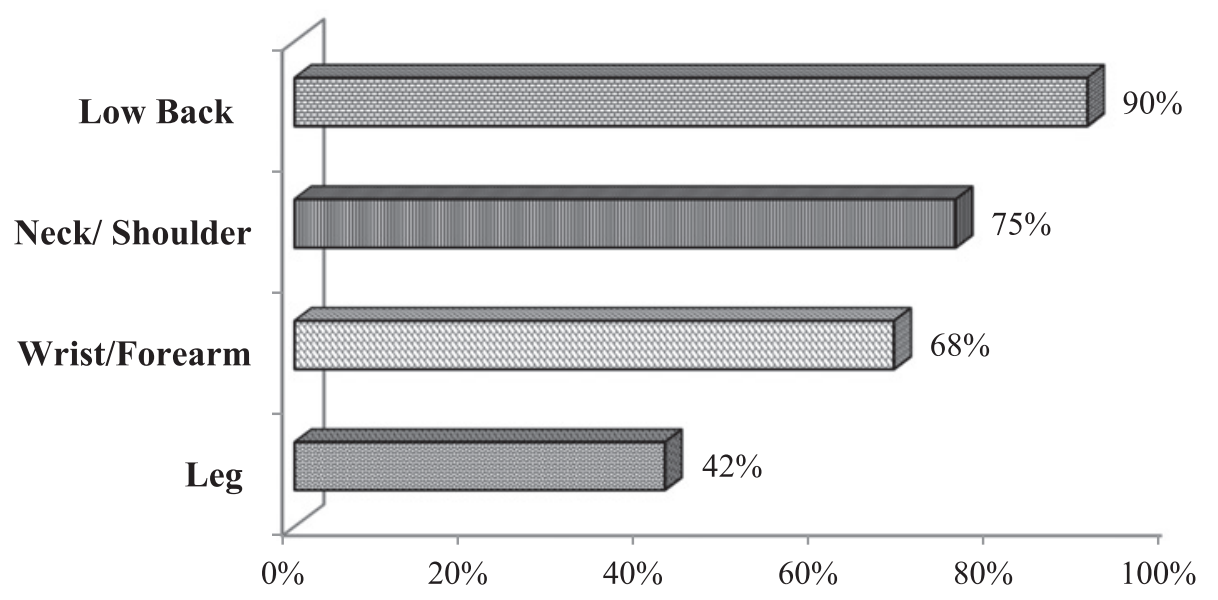

Percentage of respondents

Fig. 1. Percentage of Chikan embroiderers suffering from musculoskeletal discomfort in more than one body part $(n=400)$

Table 2. Association of musculoskeletal disorders with job autonomy, working behavior, and work stress factors $(\mathrm{n}=400)$

\begin{tabular}{|c|c|c|c|c|c|c|c|c|c|}
\hline \multirow{2}{*}{ Exposure parameters } & \multicolumn{3}{|c|}{ Lower Back } & \multicolumn{3}{|c|}{ Neck/Shoulder } & \multicolumn{3}{|c|}{ Wrist/Forearm } \\
\hline & OR & $95 \% \mathrm{CI}$ & $\mathrm{p}$ Value & OR & $95 \% \mathrm{CI}$ & $\mathrm{p}$ Value & OR & $95 \% \mathrm{CI}$ & $\mathrm{p}$ Value \\
\hline \multicolumn{10}{|l|}{ Job autonomy } \\
\hline Rigidity in work methods & 5.00 & $2.53-9.85$ & $<0.001$ & 4.69 & $2.89-7.62$ & $<0.001$ & 16.61 & $9.48-29.09$ & $<0.001$ \\
\hline Prolonged working time & 8.14 & $4.07-16.29$ & $<0.001$ & 10.19 & $5.92-17.50$ & $<0.001$ & 20.62 & $12.01-35.40$ & $<0.001$ \\
\hline $\begin{array}{l}\text { Inadequate rest break during the } \\
\text { working day }\end{array}$ & 6.20 & $3.12-12.33$ & $<0.001$ & 20.43 & $11.44-36.49$ & $<0.001$ & 8.76 & $5.42-14.16$ & $<0.001$ \\
\hline \multicolumn{10}{|l|}{ Working behavior } \\
\hline $\begin{array}{l}\text { Conflict regarding family care- } \\
\text { taker \& wage earner }\end{array}$ & 1.08 & $0.56-2.08$ & 0.95 & 0.76 & $0.48-1.21$ & 0.30 & 0.75 & $0.49-1.15$ & 0.22 \\
\hline Dissatisfaction regarding earning & 1.26 & $0.66-2.43$ & 0.60 & 6.15 & $3.76-10.07$ & $<0.001$ & 30.9 & $17.44-54.74$ & $<0.001$ \\
\hline No allowance & 0.42 & $0.20-0.89$ & 0.30 & 1.31 & $0.83-2.06$ & 0.30 & 0.96 & $0.63-1.47$ & 0.95 \\
\hline \multicolumn{10}{|l|}{ Work stress } \\
\hline Monotonous job pattern & 3.27 & $1.68-6.35$ & $<0.001$ & 3.36 & $2.10-5.38$ & $<0.001$ & 15.40 & $9.17-25.86$ & $<0.001$ \\
\hline Static sitting posture & 2.94 & $1.50-5.79$ & $<0.001$ & 3.08 & $1.91-4.97$ & $<0.001$ & & NA & \\
\hline Difficulty in falling asleep & 0.82 & $0.42-1.58$ & 0.67 & 0.95 & $0.57-1.59$ & 0.52 & 0.85 & $0.56-1.29$ & 0.52 \\
\hline $\begin{array}{l}\text { Repetitive movement of wrist \& } \\
\text { forearm }\end{array}$ & & NA & & & NA & $<0.001$ & 29.69 & $15.09-58.42$ & $<0.001$ \\
\hline
\end{tabular}

$p$ value based on $\chi^{2}$. OR=odds ratio; $95 \% \mathrm{CI}=95 \%$ confidence interval for $\mathrm{OR}$.

faction with regard to earning showed a tendency toward significance for symptoms in the lower back. Dissatisfaction with regard to earning predicted significant symptom development in the neck/shoulder and wrist/forearm. Among the work stress factors, monotonous job pattern was the significant predictor of symptom development in the lower back, neck/shoulder, and wrist/forearm. Static sitting posture significantly predicted symptom development in the lower back and neck/shoulder. Repetitive movement of wrist and forearm during embroidering was the significant predictor of symptom development in the wrist/forearm.

\section{Symptom prevalence}

Fig. 2 shows the analysis of the BPD scale at baseline, which supports the findings of the Nordic questionnaire analysis. The low back pain values on the BPD scale ranged between 9 and 10, neck/shoulder pain values ranged between 7 and 8 , and wrist/forearm pain values ranged between 6 and 7 . 


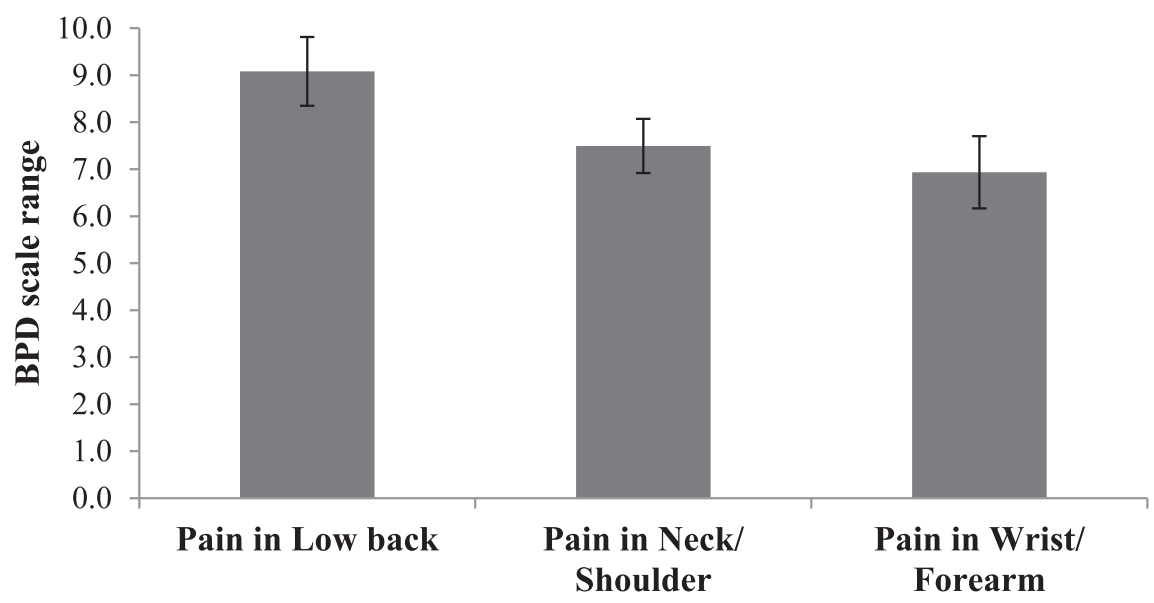

Fig. 2. Severity of musculoskeletal discomfort in Chikan embroiderers according to BPD scale analysis

Table 3. Baseline and 4-month outcomes data on two groups of embroiderers at two data points $(n=400)$

\begin{tabular}{|c|c|c|c|c|c|}
\hline \multirow{2}{*}{$\begin{array}{l}\text { Outcome measure } \\
\text { - BPD scale score }\end{array}$} & \multirow{2}{*}{ Time point } & \multicolumn{2}{|c|}{ Rest break schedule $1^{\mathrm{a}}$} & \multicolumn{2}{|c|}{ Rest break schedule $2^{b}$} \\
\hline & & Mean \pm SD & Effect size & Mean \pm SD & Effect Size \\
\hline \multirow[t]{2}{*}{ Lower Back } & Baseline & $9.1 \pm 0.7$ & \multirow{2}{*}{1.74} & $9.0 \pm 0.7$ & \multirow{2}{*}{0.29} \\
\hline & End of study & $7.7 \pm 0.9^{*}$ & & $8.8 \pm 0.7 \dagger$ & \\
\hline \multirow[t]{2}{*}{ Neck/ Shoulder } & Baseline & $7.6 \pm 0.5$ & \multirow{2}{*}{0.82} & $7.5 \pm 0.6$ & \multirow{2}{*}{0.17} \\
\hline & End of study & $7.1 \pm 0.7 *$ & & $7.4 \pm 0.6 \$$ & \\
\hline \multirow[t]{2}{*}{ Wrist/ Forearm } & Baseline & $7.0 \pm 0.8$ & \multirow{2}{*}{0.53} & $6.9 \pm 0.8$ & \multirow{2}{*}{0.13} \\
\hline & End of study & $6.6 \pm 0.7 *$ & & $6.8 \pm 0.7 \ddagger$ & \\
\hline
\end{tabular}

$* \mathrm{p}<0.001$

${ }^{\dagger} \mathrm{p}<0.05$

$¥$ Not significant

a30-min work/5-min rest

b60-min work/10-min rest

\section{Effects of rest break schedules}

Significant effects of the rest break schedules on BPD scale scores of the different body parts are presented with their corresponding effect sizes in Table 3. Rest break schedule 1 had more significant improvement on the BPD scale ratings of the lower back, neck/shoulder, and wrist/ forearm than Rest break schedule 2. Ratings for these measures indicated significantly lower discomfort levels when participants worked under the Rest break schedule 1 than when they worked under the Rest break schedule 2 .

\section{Discussion}

The primary strength of this study was that it identifies the exposure parameters for development of musculoskeletal discomfort at the baseline and indicates the effect of rest breaks schedules in reducing the severity of these symptoms at follow-up. Results of this study show that musculoskeletal discomforts are common and relatively severe in the Chikan embroiderers of West Bengal, India, and are amenable to several Ergonomics factors. Design of rest break schedule including short and frequent rest breaks reduced the severity of these discomforts among the embroiderers at follow-up.

\section{Discomfort levels and Ergonomics factors}

In the present study, body regions that received the highest discomfort ratings included the lower back, neck/ shoulder, and wrist/forearm. This pattern of discomfort is common among seated workers performing repetitive hand intensive job ${ }^{23)}$.

This study found significant associations between symptom development in the lower back, neck/shoulder, and wrist/forearm with rigidity in working methods, prolonged working time, and inadequate rest break during the working day. In various studies, it was shown that less task variety assigned to women is a prime cause of devel- 
oping MSDs $^{24,25)}$. It has long been recognized that workers with predominantly repetitive tasks, or those maintaining fixed postures for long periods of time, have an increased risk of developing musculoskeletal discomforts ${ }^{26,27)}$. Breaks are an important determinant of musculoskeletal health ${ }^{28)}$. Bergqvist et al in their study on VDT workers indicated that risk of musculoskeletal discomfort increases in workers who have limited rest break opportuni$\operatorname{ties}^{29)}$. Dissatisfaction regarding earning was a significant predictor of musculoskeletal discomfort in embroiderers. According to Hadler, dissatisfaction with a work situation greatly contributes to the onset and persistence of musculoskeletal discomforts ${ }^{30)}$. Monotonous job pattern was a significant predictor of musculoskeletal discomforts in the lower back, neck/shoulder, and wrist/forearm. Previous studies similarly concluded that monotonous work was an important factor for the development of musculoskeletal discomforts ${ }^{31-33)}$. Static sitting posture caused significant symptom development in the lower back and neck/shoulder. It has already been widely accepted in other studies that awkward static postures result in musculoskeletal stress on different body regions of seated workers ${ }^{33-35)}$. Repetitive movement of wrist and forearm was the significant predictor of symptom development in the wrist/forearm. Manual labor involving repetitive wrist movement increases the risk of developing carpal tunnel syndrome ${ }^{36}$.

\section{Rest break schedules \& effect sizes}

In the present study, Rest break schedule 1 with more frequent and shorter breaks had more significant improvement on the BPD scale ratings of the lower back, neck/ shoulder, and wrist/forearm. Several studies have confirmed that more frequent and shorter breaks cause significant improvement in musculoskeletal problems in case of light repetitive work ${ }^{37}$. The Rest break schedule 1 was designed for a 4-month period. Previous intervention study has shown that short rest pauses was significantly associated with reduced discomfort scores in different body regions at the 2-month follow up ${ }^{38}$. Balci and Aghazadeh in their study on VDT users showed that work-rest schedule designed with 60-minwork/10-minrest (60/10) and 30-min work/5-minrest (30/5) had statistically significant effects on discomfort in the neck, shoulder, lower and upper back, elbow, and arms ${ }^{39}$. Frequent rest breaks have been recommended for reducing repetitive strain injuries ${ }^{40)}$.

\section{Limitations of this study}

There were few limitations to this study, one of which was participant recruitment among the embroiderers. These women are part of a socioeconomic group that does not typically allow women to communicate with unknown people. This made it challenging for the authors to convince them to participate in the study. Because musculoskeletal discomforts were subjectively reported by the participants, the outcome assessor was the subject, who could not be visor to the intervention status. A betweensubjects design without controls was used; therefore, positive effects due to other unidentifiable factors other than rest break schedules cannot be excluded. The observed comfort improvements could have occurred over time.

Some of these study limitations could be addressed by extending trials over a longer period, adding multiple control groups or data collection intervals, and reducing awareness between groups regarding the experimental conditions.

Despite these limitations, the findings from this study demonstrate that design and implementation of rest break schedules, including brief rest breaks may reduce workers' musculoskeletal discomfort.

\section{Recommendations}

- The Chikan embroiderers must be introduced to good and safe work practices, for e.g., having back rest while embroidering and changing the working position after certain period of time.

- Training modules maybe formulated for awareness regarding safety and alleviating the severity of discomforts in different body parts. This is to be implemented by the introduction of exercise regimes.

In conclusion, the present study emphasizes that Chikan embroiderers are engaged in a highly repetitive hand intensive job requiring long hours of static work. The role of various ergonomic conditions as prognostic factors was identified for the development of musculoskeletal discomforts among them. Inadequate rest breaks in a working day was found to be a significant predictor of musculoskeletal discomforts and design of a proper rest break schedule with frequent, shorter breaks mitigated these discomforts to a considerable extent. Thus, although design of rest break schedules decreased working hours, the health of the embroiderers improved. Under better health conditions, they can perform embroidery better and work for longer duration and will ultimately earn more.

Acknowledgments: Authors express their sincere gratitude to all those Chikan embroidery workers who rendered immense cooperation during the completion of this study. Authors acknowledge the Department of Science \& Technology, Govt. of West Bengal for their partial financial assistance in this study.

The authors declare that there is no conflict of interest.

\section{References}

1) McCann M. Entertainment and the arts. In: Stellman JM, editor. Encyclopaedia of occupational health and safety. 4 th ed. Geneva, Switzerland: International Labour Office; 1998. vol. III, 96. p. 2-7. 
2) Chen M, Sebstad J, O.Connell L. Counting the invisible workforce: the case of home-based workers. World Dev 1999; 27 (3): 603-610.

3) Wilkinson-Weber CM. Skill, dependency, and differentiation: Artisans and agents in the Lucknow embroidery industry. Ethnology 1997; 36(1): 49-65.

4) Wilkinson-Weber CM. Embroidering lives: Women's work and skill in the Lucknow embroidery industry. Albany: State University of New York Press; 1999.

5) Treaster DE, Burr D. Gender differences in prevalence of upper extremity musculoskeletal disorders. Ergonomics 2004; 47: 495-526.

6) Alcouffe J, Manillier P, Brehier M, Fabin C, Faupin F. Analysis by sex of low back pain among workers from small companies in the Paris area: severity and occupational consequences. Occup Environ Med 1999; 56: 696-701.

7) Schneider S, Schmitt H, Zoller S, Schiltenwolf M. Workplace stress, lifestyle and social factors as correlates of back pain: a representative study of the German working population. Int Arch OccEnvHea 2005; 78: 253-269.

8) Choobineh A, Tosian R, Alhamdi Z, Davarzanie M. Ergonomic intervention in carpet mending operation. Appl Ergon 2004; 35(5): 493-496.

9) Canjuga M, Läubli T, Bauer G. Can the job demand control model explain back and neck pain? Cross-sectional study in a representative sample of Swiss working population. Int J Ind Ergon 2010; 40: 663-668.

10) Bingefors K, Isacson D. Epidemiology, co-morbidity \& impact on health-related quality of life of self-reported headache \& musculo-skeletal pain- a gender perspective. Evr J Pain 2004; 8(5): 435-450.

11) Christensen H, Sogaard K, Pilegaard M, Olsen HB. The importance of the work/rest pattern as a risk factor in repetitive monotonous work. Int J Ind Ergon 2000; 25: 367-373.

12) Henning RA, Kissel GV, Maynard DC. A compensatory rest break system for VDT operators: proceedings of the Human Factors and Ergonomics Society, 37th Annual Meeting. Santa Monica, CA: Human Factors and Ergonomics Society; 1993. p. $905-909$.

13) Boucsein W, Thum M. Design of work/rest schedules for computer work based on psychophysiological recovery measures. Int J Ind Ergon 1997; 20: 51-57.

14) Galinsky TL, Swanson NG, Sauter SL, Hurrell JJ, Schleifer LM. A field study of supplementary rest breaks for data-entry operators. Ergonomics 2000; 43: 622-638.

15) McLean L, Tingley M, Scott RN, Rickards J. Computer terminal work and the benefit of microbreaks. Ergonomics 2001; 32: 225-237.

16) Balci R, Aghazadeh F. Effects of exercise breaks on performance, muscular load, and perceived discomfort in data entry and cognitive tasks. ComputIndEng 2004; 46: 399-411.

17) Swanson NG, Sauter SL. The effects of exercise on the health and performance of data-entry operators. In: Luczak H, Cakir A, Cakir G, editors. Work with display units. Amsterdam: Elsevier Science; 1993. p. 288-291.
18) Kuorinka I, Jonsson B, Kilbom A, et al. Standardised Nordic questionnaires for the analysis of musculoskeletal symptoms. Appl Ergon 1987; 18(3): 233-237.

19) Barros RN, Alexandre RM. Cross-cultural adaptation of the Nordic musculoskeletal questionnaire. IntNurs Rev 2003; 50: 101-108.

20) Dickinson CE, Campion K, Foster AF, Newman SJ, O'Rourke AMT, Thomas PG. Questionnaire development: an examination of the Nordic musculoskeletal questionnaire. Appl Ergon 1992; 23: 197-201.

21) Palmer K, Smith G, Kellingray S, Cooper C. Repeatability and validity of an upper limb and neck discomfort questionnaire: the utility of the standardized Nordic questionnaire. Occup Med 1999; 49: 171-175.

22) Reynolds JL, Drury CG, Broderick RL. A field methodology for the control of musculoskeletal injuries. Appl Ergon 1994; 25: 3-16.

23) Choobineh A, Hosseini M, Lahmi M, Jazani RK, Shahnavaz H. Musculoskeletal problems in Iranian hand-woven carpet industry: Guidelines for workstation design. Appl Ergon 2007; 38: 617-624.

24) Punnett L, Herbert R. Work-related musculoskeletal disorders: is there a gender differential, and if so, what does it mean? In: Goldman M, Hatch MC, editors. Women and health. New York, USA: Academic Press; 2000. p. 474-492.

25) Dumais L, Messing K, Seifert AM, Courville J, Vézina N. Make me a cake as fast as you can: determinants of inertia and change in the sexual division of labor of an industrial bakery. Work Employ Soc 1993; 7: 363-382.

26) Wallace M, Buckle P. Ergonomic aspects of neck and upper limb disorders. Int Rev Ergon 1987; 1: 173-200.

27) Carter JB, Banister EW. Musculoskeletal problems in VDT work: a review. Ergonomics 1994; 37: 1623-1648.

28) McLean L, Tingley M, Scott RN, Rickards J. Computer terminal work and the benefit of microbreaks. Appl Ergon 2001; 32: 225-237.

29) Bergqvist U, Wolgast E, Nilsson B, Voss M. Musculoskeletal disorders among visual display terminal workers: individual, ergonomic and work organizational factors. Ergonomics 1995; 38: 763-776.

30) Hadler NM. Occupational musculoskeletal disorders. Philadelphia (PA): Lippincott Williams \& Wilkins; 1999.

31) Bongers PM, de Winter CR, Kompier MA, Hildebrandt VH. Psychosocial factors at work and musculoskeletal disease. Scand J Work Environ Health 1993; 19: 297-312.

32) Burdorf A, Sorock G. Positive and negative evidence of risk factors for back disorders. Scand J Work Environ Heath 1997; 23: 243-256.

33) Sarna T, Shukla A. A study of physical-health and neuroticism among women engaged in the home-based production of chikan embroidery. Soc Indic Res 1994; 32: 179-191.

34) Gangopadhyay S, Ray A, Das A, et al. A study on upper extremity cumulative trauma disorder in different unorganized sectors of West Bengal, India. J Occup Health 2003; 45: 351357. 
35) Gangopadhyay S. Humanizing Work and Work Environment: A challenge for developing countries [Guest Editorial]. Work 2012; 43: 399-401.

36) Frost P, Andersen JH, Nielsen VK. Occurrence of carpal tunnel syndrome among slaughterhouse workers. Scand J Work Environ Health 1998; 285-292.

37) Mital A, Kopardekar P. The effect of different work-rest schedules on fatigue and performance of a simulated directory assistance operator's task. Ergonomics 1994; 37: 1697-1707.
38) Ketola R, Toivonen R, Häkkänen $M$, et al. Effects of ergonomic intervention in work with video display units. Scand $\mathrm{J}$ Work Environ Health 2002; 28(1): 18-24.

39) Balci R, Aghazadeh F. The effect of work-rest schedules and type of task on the discomfort and performance of VDT users. Ergonomics 2003; 46: 455-465.

40) Fisher DL, Andres RO, Airth D, Smith SS. Repetitive motion disorders: the design of optimal rate-rest profiles. Hum Factors 1993; 35: 283-304. 